\title{
APROXIMACIÓN GRÁFICA Y ESCALAR AL PAISAJE Y AL PATRIMONIO TERRITORIAL EN EL OCCIDEN- TE DE CASTILLA Y LEÓN
}

\author{
Esther Isabel PRADA LLORENTE \\ Departamento de Arquitectura. Universidad de Alcalá de Henares
}

Recibido: 10/02/2011

Aceptado: 04/07/2011

RESUMEN: El artículo explora la utilización de la expresión gráfica como lenguaje de referencia y el entendimiento del paisaje y el territorio como un sistema, elementos necesarios para el establecimiento de una guía de buenas prácticas para la observación del paisaje agrario como espacio patrimonial en el occidente castellano-leonés, capaz de contribuir a una depuración de las formas y prácticas de planificación heredadas de lo urbano, desposeedoras del entramado de prácticas territoriales, códigos pretéritos y modos de relación entre sociedad y territorio, que han generado un paisaje por la experiencia como procesos de acumulación primitivos.

Se acomete el estudio gráfico comparado que abarca las provincias de León, Zamora y Salamanca a través de tres comarcas, Valduerna, Tierra de Sayago y Tierra de Vitigudino, pertenecientes a este ámbito geográfico del oeste de Castilla y León, desde la metodología de trabajo fundamentada en un término municipal representativo para cada una de ellas como unidad de investigación más conveniente.

Se plantea la evocación y representación de la imagen de este ámbito geográfico, de su paisaje, de la totalidad del "sistema paisaje agrario", mediante los elementos patrimoniales que se sitúan en cada una de las escalas territorial, urbana y arquitectónica, necesarias para la comprensión de la totalidad de dicho sistema. Los elementos pertenecientes a cada una de ellas fundamentan la identificación de la singularidad paisajística de este espacio, basada en la construcción histórica de este territorio. A través de cada una de las citadas escalas se comprueba la diversidad de respuestas ante la gestión del medio tal y como se manifiestan en el paisaje, para lo cual se eligen los casos de un municipio no concentrado, otro con concentración parcelaria reciente - año 1999- y un tercero con concentración parcelaria antigua - años setenta del pasado siglo-, correspondiéndose cada uno de estos estados con los municipios elegidos de Salamanca, Zamora y León respectivamente, recuperando en la medida de lo posible, las bases ecológicas, históricas y culturales de este territorio como fundamento de intervenciones futuras sobre el mismo..

PALABRAS CLAVE: Paisaje agrario, expresión gráfica, sistemas, patrimonio territorial.

\section{A GRAPHICAL AND SCALAR APPROACH TO LANDSCAPE AND SPATIAL HERITAGE IN WESTERN CASTILE AND LEON (SPAIN)}

ABSTRACT: This paper explores the use of visual art skills as a reference language for the interpretation of landscape and territory. Both spatial components are conceived as a system 
to be decoded, aiming at a good practice guide for the agrarian landscape in the West of Castile and Leon, a Spanish region. The current forms and planning practices are inspired in urban models, and the result is a weakening of the links between society and space, and dysfunctional practices causing accumulative disruption of the landscape.

Graphical means are used within the frame of a comparative approach, whereby three districts, each one located in a different province (Valduerna in León, Sayago in Zamora and Tierra de Vitigudino in Salamanca) are considered. All three areas belong to the Western part of Castile and Leon. The method is based on the analysis of a representative municipal area in each of the three districts under consideration.

The visual representation and the connotative aspects associated to it are addressed as a connected structure, so as to produce a global portrait of the landscape. The whole is understood as an "agrarian landscape system", and the heritage associated to it may belong to either of three scales: territorial (the whole municipal area), urban (built-up area) and architectonical. Different items belonging to the three scales provide a token of the singularity, in terms of landscape, of each one of the areas. This singularity is a result of a historical construction process. The three scales show the diversity of land planning and its effects. To that end, one of the villages, in Salamanca, has never been subject to plot redistribution (concentración parcelaria), the other one, in Zamora, underwent a recent process, in 1999, and the third one was concentrated in the 1970s. The aim is to document as far as possible the ecological, historical and cultural bases of the territory, as a precondition for future spatial management.

KEY WORDS: Agrarian landscape, graphical expression, systems, territorial heritage.

\section{INTRODUCCIÓN: IMAGEN CULTURAL Y EXPERIENCIA DEL PAISAJE FRONTERIZO CASTELLANO Y LEONÉS}

Las páginas que siguen ${ }^{1}$ podrán resultar extrañas, acostumbrados como estamos a los retratos consoladores y a las versiones oficiales sobre paisaje natural, paisaje rural, paisaje tradicional o paisaje agrario, expresiones todas ellas muy ligadas al entramado de prácticas territoriales asociadas a ellos, formas de derecho que respondían a un régimen autogestionado colectiva-

\footnotetext{
${ }^{1}$ Me siento agradecida por tener la oportunidad de escribir para la revista Polígonos en este monográfico dedicado al paisaje agrario de Castilla y León, así como a los evaluadores que han aportado su opinión para mejorarlo. Puede parecer tonto, o escasamente académico afirmar que es de esas cosas que hacen que me sienta bien. Es agradable que cuenten conmigo para esta tarea y poder hacerlo me permite, ante estos años convulsos que estamos viviendo, hacer acopio de la mejor energía para exponer, tomando conciencia, las transformaciones que están sucediendo en el paisaje y entorno de mi infancia. Somos y formamos parte de un sistema que se nutre de muchas cosas, todos vamos creando experiencias que consciente o inconscientemente hemos elegido. Ahora se trata de crear un estado de cosas, que nos permita alimentar nuestra alma con las mejores emociones. Es posible que el lema que cada uno de nosotros nos podríamos aplicar en el presente estado de la cuestión diría algo así: Si algo no te gusta, actúa.

Parte de este texto y la interpretación gráfica se enmarca dentro del proyecto de investigación: Las unidades básicas de paisaje agrario en España: identificación, delimitación, caracterización y valorización. La España interior, septentrional y occidental (Referencia CS02009-12225-C05-01, Ministerio de Ciencia e Innovación).
} 
mente, así como a la historia cotidiana de los pueblos que descansa en las viejas casas, arroñadas por el tiempo y por el abandono, en las que podía leerse también la historia constructiva de un territorio. Frente a la afectación de muchas construcciones contemporáneas, estas casas ofrecen ante las leyes de su entorno, un sabio y elemental sometimiento. Cuando las miramos, algo familiar emerge de nuestra memoria a nuestros ojos, ya desacostumbrados al uso de materiales como la piedra, el barro o la paja.

El presente artículo pretende sumarse a los esfuerzos de revisión crítica frente a las formas de planificación de un entorno rural periférico, entendidas como estrategias de poder sobre el espacio. Como hemos señalado en otro lugar (PRADA, 2010), tal revisión implica la reconstrucción de nuestro pasado. Necesitamos una historia social del territorio y del paisaje, para otorgar una nueva legitimidad a nuestras técnicas, fundadas en el compromiso con la cultura territorial.

En el ámbito geográfico occidental de Castilla y León, provincias de León, Zamora y Salamanca, encontramos un entramado de prácticas territoriales fijadas en la baja Edad Media y ligadas a la propiedad comunal (PRADA, 2005), en las que la ciudad no tiene mucho que decir. Por el contrario, es en el medio rural donde encontramos una relación total entre territorio y sociedad, dado que dichas prácticas no responden a ningún modelo estructural previamente planificado, un soporte territorial plagado de códigos pretéritos que se reflejan en el paisaje, ajenos al mercado. Este nuevo orden dominante, surgido en la segunda mitad del s. XIX, en el ámbito que nos ocupa fundamentalmente en la segunda mitad del s. XX, en un proceso que continúa durante estos primeros años del s. XXI, consume paulatinamente su entorno destruyendo esas formas de vida prosperando a su costa. El nuevo orden se construye para desterritorializar el antiguo tejido social, formas jurídicas tales como las planificaciones urbanas o la concentración parcelaria en apariencia limitadas a la reconfiguración de las estructuras de propiedad rural.

La apariencia del paisaje tradicional en este entorno geográfico, así como en la práctica totalidad de los espacios agrarios patrimoniales, no deriva de un diseño, de una planificación, sino de la iteración en el tiempo de una forma de uso, una resultante involuntaria de procesos agregados de interacción con el medio. Las comunidades rurales tradicionales ya prácticamente extintas, generaron un paisaje derivado de su cotidianeidad consiguiendo además, efectos compositivos de belleza orgánica.

La gestión compartida del territorio entre comunidades de pastores y agricultores en el occidente castellano-leonés que suponía determinadas formas de uso, tales son la comunalidad de los pastos y aprovechamientos de rastro- 
jeras y cultivos, produjo como resultado los paisajes de mosaico, los cortineos, los campos comunales abiertos o las dehesas (PRADA, 2005).

La evolución del paisaje en este espacio a través del estudio de Valduerna, Sayago y Vitigudino ${ }^{2}$, refleja que sólo una pequeña fracción de población, algunos viajeros y turistas, que se expande al mismo compás con que se va extinguiendo el mundo rural, valora esta belleza orgánica heredada y el patrimonio territorial que aún atesora este ámbito geográfico.

El aprecio por este paisaje es relativamente minoritario, como ya señalan diversos autores (RIESCO, 2008), los trabajadores que perviven en estas comarcas de la agricultura o la ganadería no perciben como bello su entorno al estar asociado a una vida de trabajo, las clases generalmente urbanas y adiestradas estéticamente por la televisión y el consumo, tienden a situar la belleza en otros lugares, los museos, los monumentos, los parques temáticos.... La televisión, como formador del canon estético contemporáneo, determina la imitación de paisajes y arquitecturas tales como el chalet, el césped, la balaustrada, el paisaje de urbanización o planificado, que no vienen avaladas empíricamente como lo estaba el paisaje rural tradicional, originándose así la emergencia de paisajes-pastiche y el acarreo caótico de elementos prefabricados, la agricultura oportunista y la fragmentación de las tramas naturales, creando un marco difícil de asimilar estéticamente, produciendo una pérdida de dignidad del paisaje, convertido en vertedero y poblado de elementos dispersos.

Esta desterritorialización se refleja en la distribución caótica de las naves ganaderas, los silos... afianzándose la compartimentación del territorio, función agraria, función residencial o turística y dispersión sobre islotes de paisaje tradicional, -separación de funciones o urban sprawl (NAREDO, 2004)resultado de la planificación y el gusto por lo urbano, que conlleva a un tapiz degradado de naturaleza residual (PRADA, 2010), en el que se asientan formas advenedizas, naves-ovni, pistas rectilíneas y caminos de concentración, alambradas, plásticos, chapas..., con débiles relaciones con el lugar, tales formas no son perecederas y carecen de la capacidad para disolverse en el entorno. Dado que la intensidad de las modificaciones en la agricultura o la construcción contemporáneas es muy acusada, a medida que avanza la degradación, las oportunidades de un territorio para ingresar entre los "bende-

\footnotetext{
${ }^{2}$ Así mismo, parte de las reflexiones aquí planteadas se enmarcan dentro de la realización de la Guía de Buenas Prácticas para la observación del paisaje agrario como espacio patrimonial en el Oeste Peninsular. Agradezco a Pascual Riesco de la Universidad de Sevilla, Tomás Herrero de la UPM y al grupo Altekio, su colaboración conmigo para la realización de este trabajo promovido por el MARM.
} 
cidos por el canon", parques naturales o parajes protegidos, van reduciéndose (RIESCO, 2008). Debemos ser conscientes de esa degradación dictada por el nuevo orden, el mercado.

El repliegue sensorial hacia los micro-paisajes en esta situación, es lo que nos queda para encontrar pequeños rincones donde todavía es posible detectar un resto del antiguo tejido territorial, del antiguo pueblo, o de la antigua casa; como señala Martínez de Pisón, la imagen de la cultura de un territorio, es decir, una forma geográfica más su conocimiento, un modo de relación con aquella, de entenderla (MARTínEZ DE PISÓN, 2006).

En este sentido el hecho de acercarse a través de la imagen, reinterpretando y dibujando, re-presentando algunos fragmentos-rincones de este paisaje agrario en el occidente castellano y leonés como se desarrolla a continuación, implica tanto un modo de relación y percepción del mismo, como una lectura concreta de lo visible a través de la que revelar su identidad o singularidad como lugar. Aproximarse de esta forma a este paisaje por tanto, supone mostrar una determinada visión, un determinado punto de vista, con el propósito de enriquecer nuestra experiencia sobre este espacio de Castilla y León.

Con la paulatina extinción de las instituciones comunales, en el ámbito que nos ocupa no tan lejana en el tiempo, -existen municipios en Sayago en los que aún perviven estas formas de gestión territorial- vieron el relevo los embriones del diseño de ciudad, operando sistemáticamente sobre campos previamente organizados por el paisaje de mosaico, adoptando formas regladas y respaldadas por instituciones públicas, reescribiendo los códigos de reproducción social que articulaban el territorio.

A estos códigos, a modo de retazos de este paisaje heredado, nos aproxima Ángel Cabo Alonso ${ }^{3}$ mediante sus recuerdos y experiencias vividas, su pun-

\footnotetext{
${ }^{3}$ Agradezco a D. Ángel Cabo el esfuerzo que ha realizado, las conversaciones con él mantenidas y la redacción de este texto, presentación de la exposición Guía de Buenas Prácticas para la observación del paisaje agrario transfronterizo como espacio patrimonial: la comarca de Sayago, mostrada en Zamora en Julio de 2009. Para ello recurrió a su documentación de antaño y relativa a su conocido trabajo sobre el Colectivismo Agrario en las Tierras de Sayago, publicado por la revista Estudios Geográficos del Instituto Juan Sebastián El Cano del CSIC, así como a sus recuerdos de los días pasados por estas tierras y con sus gentes, fundamentalmente en Muga de Sayago, a finales de la década de los cincuenta del pasado siglo. El texto lo he transcrito según él me lo remitió impreso en papel, por tanto, el documento en sí constituye una nueva aportación respecto a las antiguas formas comunales, necesarias para la comprensión de este territorio y su paisaje. La citada exposición ha sido mostrada en la Iglesia de la Encarnación de la Diputación de Zamora, en el Centro de Interpretación del Bajo Tormes en Monleras (Salamanca), Asociación de Empresarios de Sayago en Bermillo (Zamora),
} 
to de vista geográfico expresado en el texto aquí transcrito, con el que la autora que suscribe le rinde su más sincero agradecimiento.

"Sayago es el nombre que damos a una de las comarcas que comprende la provincia de Zamora y, también, al batolito granítico sobre el que la misma comarca se asienta.

Además de esta surgencia rocosa, otra particularidad física destaca en el conjunto: está limitado por dos importantes corrientes fluviales: la del Duero y la del Tormes, afluente suyo. Una y otra vienen con sosegado discurso por llanuras de la misma provincia zamorana pero, ya adentradas, en la comarca se encrespan, encajan y ahondan su cauce. De tal manera que la duriense sirvió para que en ella se estableciera la separación fronteriza entre los dos Estados peninsulares. En cualquier caso, los encajamientos facilitaron el aprovechamiento energético aunque no las relaciones humanas: los lugares sayagueses -Fariza, Cozcurrita, Badilla, Argañín, Tudera, Pinilla de Fermoselle, Formariz, Fornillos de Fermoselle, Palazuelo de Sayago, Mámoles- levantan sus caseríos a varios centenares de metros de altitud, en tanto que la frontal de uno y otro río se limita a unas decenas de metros; esto es, aquí los núcleos de población vuelven la espalda a las corrientes acuáticas. Incluso el paraje conocido como de las Dos Aguas, porque en el confluyen ambas, tampoco acoge poblamiento alguno. Cabe decir, que los ríos sayagueses han actuado más bien como barreras que como nexo. Es significativo que, para traspasar la frontera, la coronación de las presas se utilicen como pasos peatonales y de vehículos y que en el pueblo portugués inmediato se haya montado un mercado que sirve a públicos de ambos países y origina la repoblación lusitana del lugar, Miranda do Douro.

Así, las gentes de la comarca sayaguesa, horras de influencias fluviales y fronterizas, se han volcado en la contemplación y la utilidad del propio terruño. Trascienden esas características a las denominaciones geográficas: la de gamones, por ejemplo, que es el nombre del asfodelo, planta liliácea abundante en los prados de la región. A este respecto procede señalar que la toponimia menor está preñada aquí de alusiones a esa riqueza botánica y al papel importante o a la admiración que provocó entre los repobladores medievales: El Encinar en Pereruela; Los Robles, en Sobradillo de Palomares; El Rebollar, en Salce y Cibanal; El Enebro, en Badilla. También son dignas de mención las referentes a especies arbustivas, como las retamas, que es a lo que responden El Escobalón de Formariz y Las Escobadas de Pinilla de Fermoselle...Más abundantes, como es la exigencia de su mayor

\footnotetext{
Escuela de Arquitectura de la Universidad de Alcalá, Escuela de Ingenieros Técnicos Agrícolas de la Universidad Politécnica de Madrid, Casa del Parque en Fermoselle (Zamora), Casa del Parque en Sobradillo (Salamanca) y Escuela de Arquitectura de la Universidad de Valladolid, encontrándose en el momento de escribir el presente artículo en la sede del Centro de Estudios Hispano-Lusos de la Fundación Duques de Soria en Ciudad Rodrigo (Salamanca).
} 
presencia, son los robles, de los que tenemos no pocas alusiones: El Carballo, de Fornillos; La Carba, de Salce y de Piñuel; Las Carbas de Villar del Buey; Las Carbitas, de Muga de Sayago; etc. E igualmente cabe encontrar en el agro sayagués palabras de añejo empleo cuya significación exige el rastreo en diccionarios como La Josa de Abelón, nombre que antaño se daba a una heredad no cercada y plantada de vides y frutales.

El campo sayagués muestra bien sus caracteres: basta una simple y rápida ojeada para percibir el relieve que ha tenido el agro en la vida de sus moradores: bien patentes se presentan las expresiones de sus actividades en los cortinales - "pedazos de tierra cercados inmediatos a un pueblo o a casas de campo, que ordinariamente se siembran todos los años", según reza la definición académica-. Y, sobre todo, los grandes bloques de granito con los que se cercan esos predios y sus cultivos, típicos para individualizar tradicionalmente la propiedad. Y para distinguirla bien de los bienes comunales, tan característicos del campo sayagués. A esa forma de propiedad o de posesión del agro responde otro topónimo: el de los quiñones o "suertes". Aluden a los espacios que estuvieron sometidos al reparto bianual del barbecho que se hacía en todos los pueblos para individualizar el trabajo y la posesión de la tierra concejil, la labrantía, el monte y el número de cabezas al que cada vecino tenía derecho en el aprovechamiento común del pasto. Se trata de un colectivismo que ha existido aquí al menos desde tiempo de los vacceos. Ya llamó entonces la atención de Diodoro Sículo, historiador griego del siglo I a. J.C. y el fenómeno ha sido estudiado después por sucesivos historiadores del Derecho hasta Joaquín Costa. A beneficiarse de tales repartos e individualizaciones podían acudir quienes tuvieran la condición de vecinos, incluidos el párroco, los maestros y el médico, además de los labriegos. Claro es que también todos ellos estaban obligados a participar en la poda, el desbroce, la limpieza y demás tareas montaraces y en las propias de roturar la tierra y labrar la que, sin someterla al periódico reparto, permanecía para adjudicar debido a otras circunstancias.

Esas relaciones con la tierra han trascendido también a la toponimia de la comarca. Se encuentra en Las Concejas y La Conceja de Mogátar, claras alusiones al espacio que pertenecía al municipio. Y, por supuesto, los Quiñones de Abelón y El Ejido de Muga de Sayago. Y, lo que puede parecer más extraño, la Campana de Bermillo y Peña La Campana de Villamor de la Ladre: en un puro colectivismo, la campana alude al espacio comunal del término municipal que era todo el territorio al que alcanza el sonido del campaneo de la torre de la iglesia parroquial. De todas esas denominaciones ha quedado constancia a pesar del moderno desuso. La parte labrantía, montaraz o de pasto, o la porción de tierra que se tenía por razones de los repartos, ha continuado definiéndose como un quiñón, aunque haya perdido el significado que tuvo. Habrá ahora a quién las noticias de esas prácticas comunales les parecerán insignificantes, pero han existido hasta bien entrado el siglo XX y con notable robusted. En el campo de Torregamones, por 
ejemplo, según noticias catastrales, la propiedad concejil comprendía en 1622 el 56,2 por ciento de la total agraria del término. No en todos los términos municipales llegó el espacio comunal a tan altos valores. En los más próximos a la raya, con corto terruño de laboreo, los sorteos del rural que se individualizaba y los repartos de madera y leña o del número de reses con el que cada uno podía participar en el pasto comunal tuvieron más importancia. A la llamada a sorteo a toque de campana, en general el primer domingo de otoño, acudían todos los vecinos: cada uno se situaba al exterior de uno de los ejes de la gran circunferencia que se había marcado en el suelo, y así se procedía a sortear el barbecho y el aprovechamiento montaraz y de pastizal, todo de acuerdo con los lotes o quiñones fijados previamente por la junta de labriegos que se consideraban más entendidos y con anterioridad. Todos los vecinos tenían derecho a participar en el sorteo, y tenían condición de vecino el párroco, los maestros, el secretario del ayuntamiento, el boticario, donde lo hubiera, y los labradores que estuvieran residiendo en el lugar y con labor ya montada.

Han existido estas costumbres hasta que el éxodo rural las ha hecho inoperantes. O hasta que la tierra y el pastizal dejaron de provocar interés en quiénes se mantenían ajenos a las tentaciones de la huida hacia las ciudades. En 1930 el padrón municipal comprensivo de todo Sayago, que tenía a Bermillo como cabeza, abarcaba 44 municipios, cifra que se ha reducido a pesar de las anexiones. Entonces Almeida, Bermillo de Sayago, Fariza, Fermoselle, Figueruela, Fresno de Sayago, Moraleja de Sayago y Pereruela sobrepasaban cada uno el millar de habitantes. En los padrones del del año 2005, sólo alcanzan esa cifra Bermillo y Fermoselle. A la vez, han reducido sus cifras censales los demás municipios, en muchos casos en proporciones acusadas, de tal manera que Alfaraz, Argañín, Cabañas de Sayago, Gáname, Salce y Villardiegua de la Ribera nada más cuentan en cada caso con uno o dos centenares de habitantes. Sin embargo, por toda la comarca pueden contemplarse todavía aquellos grandes bloques de granito que se arrastraron y levantaron para fijar las cercas que individualizaban la propiedad privada $o$ la diferenciaban de los abertales o porciones de espacios comunales.

Todo ello digno de un estudio esclarecedor que es el que, felizmente, ha acometido y presenta aquí, con fines didácticos, la arquitecta doctora Prada Llorente."

Ángel Cabo Alonso
Mayo 2009

Delimitar el espacio, fragmentarlo, marcar los confines de lo propio, tal parece la reacción instintiva del hombre ante la tierra, creando para ese fin, los muros que invaden poco a poco el paisaje abierto, en un intento de abarcarlo también y hacerlo más humano, las cortinas, los huertos..., la mayoría 
de las veces al cuidado de las mujeres. El paisaje ya no será el mismo sin las cortinas.

Figura 1. Pared de piedra seca

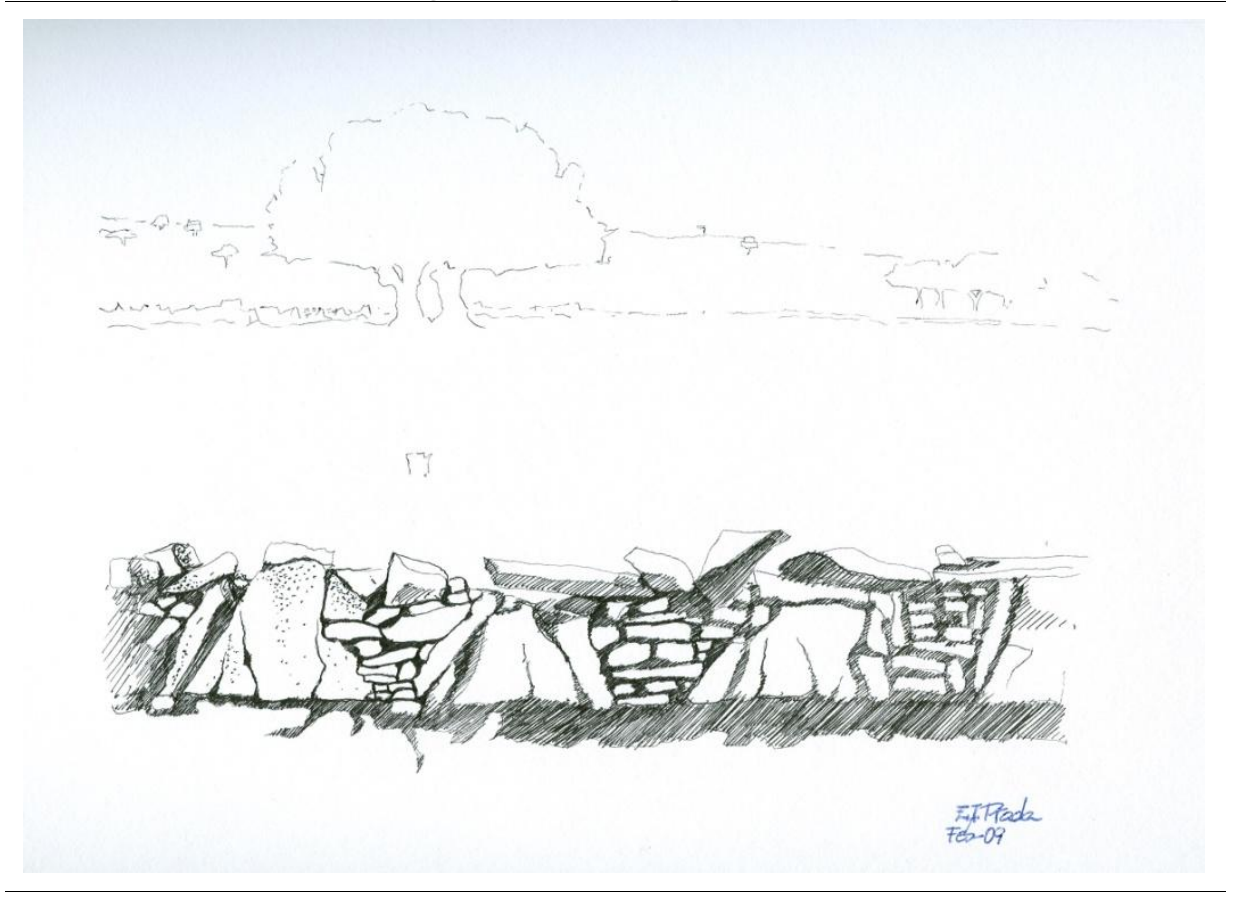

FuENTE: La autora, 2009. Tinta y lápiz

\section{LECTURA DEL PAISAJE COMO SISTEMA}

La construcción histórica del territorio implica, como muy bien expresa D. Ángel Cabo, la lectura del paisaje como si de un texto se tratara. Es necesaria la búsqueda de relaciones que mantienen los diferentes elementos, biogeográficos, antrópicos, toponímicos, lingüísticos y perceptivos, examinando como se han estructurado para formar un conjunto coherente, todos estos elementos agrupados según diferentes etapas o escalas, generan un sistema. Percibidos, evocados y representados además gráficamente, reflejan la visión que desde la formación arquitectónica nos planteamos de la realidad, la naturaleza o la experiencia de una vida ya desaparecida. La homología escalar que se expone, es la que va dando determinación a ese escenario territorial del occidente de Castilla y León y al proceso o curso que constituye su argumento, destacando las condiciones que hacen posible su entendimiento final. 
La escala, como sucesión ordenada de elementos o estructuras de la misma especie, constituye el tamaño de un sitio, generando un proceso que se configura como el curso en que cada una de las etapas o categorías, entendiendo como tales desde el soporte físico y la escala territorial a la urbana y arquitectónica, se relacionan de forma tal que, la primera prepara la segunda, esta constituye la condición de la tercera y así sucesivamente, como una sucesión o engarce en la que todos los elementos se condicionan (Prada, 2005). Los diferentes elementos agrupados en cada una de las etapas, entendiendo como tales tanto los naturales como las intervenciones realizadas sobre un soporte, configuran junto con éste, la singularidad y características del lugar objeto de estudio, Valduerna, Sayago y Vitigudino, a modo de indicadores sobre el estado general de su paisaje agrario.

Dichas intervenciones suponían tradicionalmente, una sucesión lógica de actuaciones en función de la interacción de procesos y formas de uso con el medio avaladas por la experiencia, estableciendo en cuanto a intervenciones constructivas su escala, o por el contrario, suponen en la actualidad, intervenciones destructivas que a fuerza de ser de todos los sitios no son de ninguno, rompiendo su escala al prescindir de aquellos elementos indicadores de su paisaje y referentes de la singularidad del lugar como se ha expuesto previamente.

En el curso del proceso, el soporte físico o paisaje natural constituiría la primera etapa que abre el recorrido y movimiento que culmina en el entendimiento del territorio. Dentro de este escenario que interviene a modo de hábitat, se determinan los diferentes hitos desde los que puede establecerse el entendimiento de este paisaje. Las escalas unidad territorial mínima o municipio, urbana y arquitectónica, para cada una de las comarcas estudiadas de León, Zamora y Salamanca, constituirían dichos hitos. Aglutinarían los elementos en tanto que intervenciones sobre el soporte o hábitat, para la resolución del argumento que constituye el proceso de entendimiento en cada uno de estos tres escenarios territoriales.

Las reglas del proceso espacial de construcción de los mismos, se fundamentan a su vez en la célula elemental o primaria, la casa, que genera según un proceso de agregación de dichas células una homotecia u homología, un "sistema" de ocupación del territorio, en el sentido de ser una organización espacial de categorías, escalas o etapas, así como una ordenación de recintos (ver FIG. 2).

En el presente objeto de estudio, esta organización espacial es una función de la forma de solidaridad social tradicional, la propiedad comunal o communitas civium, de carácter indivisible entre los vecinos propietarios, que lo 
son, a título de pertenecientes a dicha comunidad aldeana y que llegarían a ser inalienables e imprescriptibles ante su continua usurpación. Estas propiedades comunales, de origen germánico, suelen ser obviadas en interpretaciones o explicaciones sobre la propiedad, enfocada exclusivamente hacia la propiedad pública de un ente público -bienes de propios de los Ayuntamientos y patrimonios estatales-, o a la propiedad privada (GARCÍA-BELLIDO, 1999).

La cuestión sitúa esta disquisición, en un problema de escalas de referencia sobre el uso del espacio común y como tal, reflejado en el paisaje con unas formas determinadas y concretas.

Figura 2. Homotecia fractal de los ámbitos escalares en su evolución hacia una creciente complejidad espacial

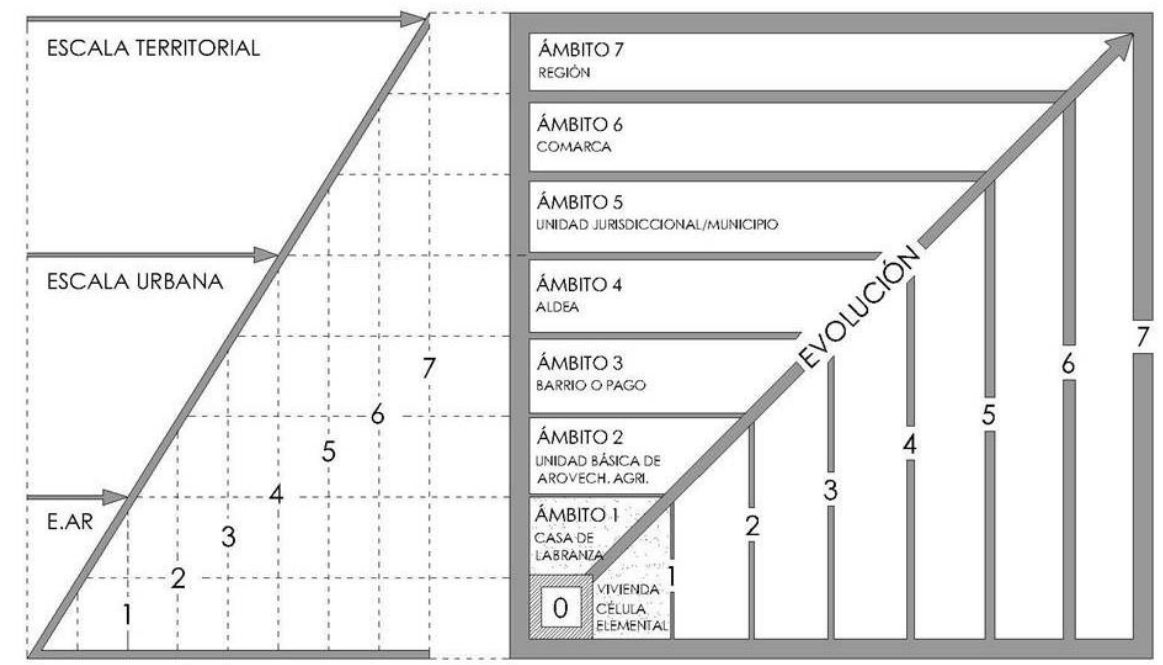

Fuente: Coranomía. Javier García-Bellido GarCía De DiegO, 1999. Elaboración Esther I. Prada Llorente

\section{DIBUJO Y PAISAJE}

La visión de la realidad a través de la formación arquitectónica, supone para la autora que suscribe además de lo ya expuesto, la utilización del dibujo como herramienta para investigar el espacio, la luz, el color, las texturas... en el paisaje ${ }^{4}$ (ver FIG. 3, FIG. 5, FIG. 6 y FIG. 7).

\footnotetext{
${ }^{4}$ Merece una especial mención el dibujo arquitectónico y de paisaje del arquitecto Efrén García Fernández, fundamentalmente el referido al ámbito geográfico leonés por la proximi-
} 
También el lugar, el lugar afectivo, percibido a través del lugar físico. Como señala John Berger, cada lugar, ha sido afrontado, arrullado, escuchado ..., para una vez dentro, disponer del mejor modo posible su apariencia, haciéndolo más nuestro; a través del dibujo afirmamos lo visible que nos rodea que está continuamente apareciendo y desapareciendo. Posiblemente sin la desaparición, no existiría el impulso de pintar o dibujar, pues entonces lo visible poseería la seguridad, la permanencia que la pintura lucha por encontrar (BERGER, 2000) (ver FIG. 4).

El dibujo es una forma de comunicación, aunque lo que parece una creación, no es sino el acto de dar forma a lo que se ha recibido, transformándose en un lenguaje que puede expresar sentimientos, sensaciones o emociones, no necesariamente los mismos que ha sentido el autor del mensaje aunque si, aquellos susceptibles de tender un puente entre autor y observador.

Dibujar un paisaje significa además, enfrentarse con el horizonte, una línea imaginaria que liga elementos como el cielo y la tierra, a través de la que se muestran la horizontalidad y verticalidad de ese paisaje desde este punto de vista frontal, aunque significativamente el elemento natural que muestra este criterio de manera más explícita según diferentes autores sería el árbol, apareciendo en la rotunda presencia del tronco y a veces, en sus ramas principales (BÁEZ, 2008) (ver FIG. 8 y FIG. 9).

La percepción de los diferentes elementos reflejada en la representación gráfica que se muestra, supone una propia y personal imagen mental de este territorio y su paisaje. Representar gráficamente significa "un paseo por el paisaje", un paseo por cada escala de paisaje hasta que la mirada queda apresada por algo, por un fragmento-rincón que la engancha, proyectándose una forma de mirar los objetos a través del dibujo, en un determinado estado en su camino hacia la nada (ver FIG. 10).

El territorio es una unidad que presupone una escisión en sus partes integrantes. Posee ciertas formas, figuras, trazos y componentes naturales, la representación de sus elementos constituyentes agrupados en los diferentes hitos, soporte/hábitat, urbano y arquitectónico, puede establecer el entendimiento de este espacio, de este escenario territorial objeto de estudio.

Mediante los dibujos aquí mostrados, se propone una lectura del paisaje en el occidente castellano y leonés, como fragmentos de realidades práctica-

dad al objeto del presente estudio. Asimismo el dibujo y la forma de expresión gráfica de Julio Caro Baroja y del arquitecto Fernando García Mercadal, suponen importantes referencias para la autora que suscribe. 
Figura 3. Espacio

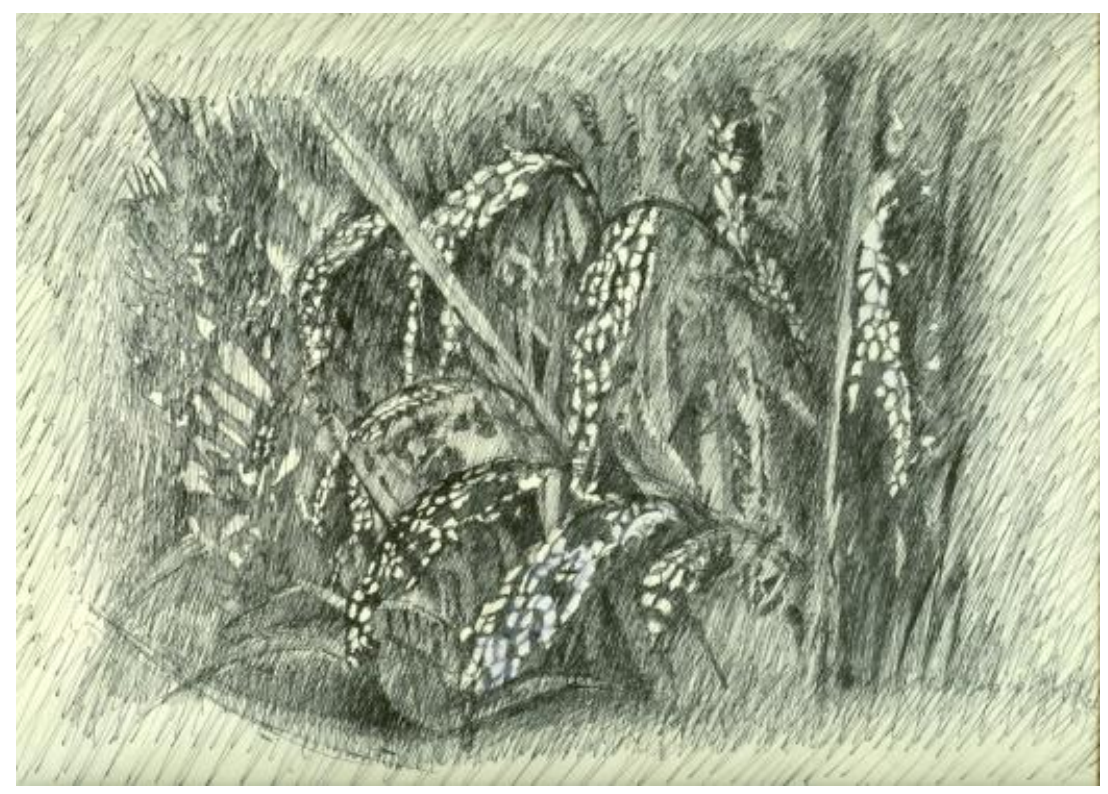

FuENTE: La autora, 2006. Tinta

Figura 4. Lugar

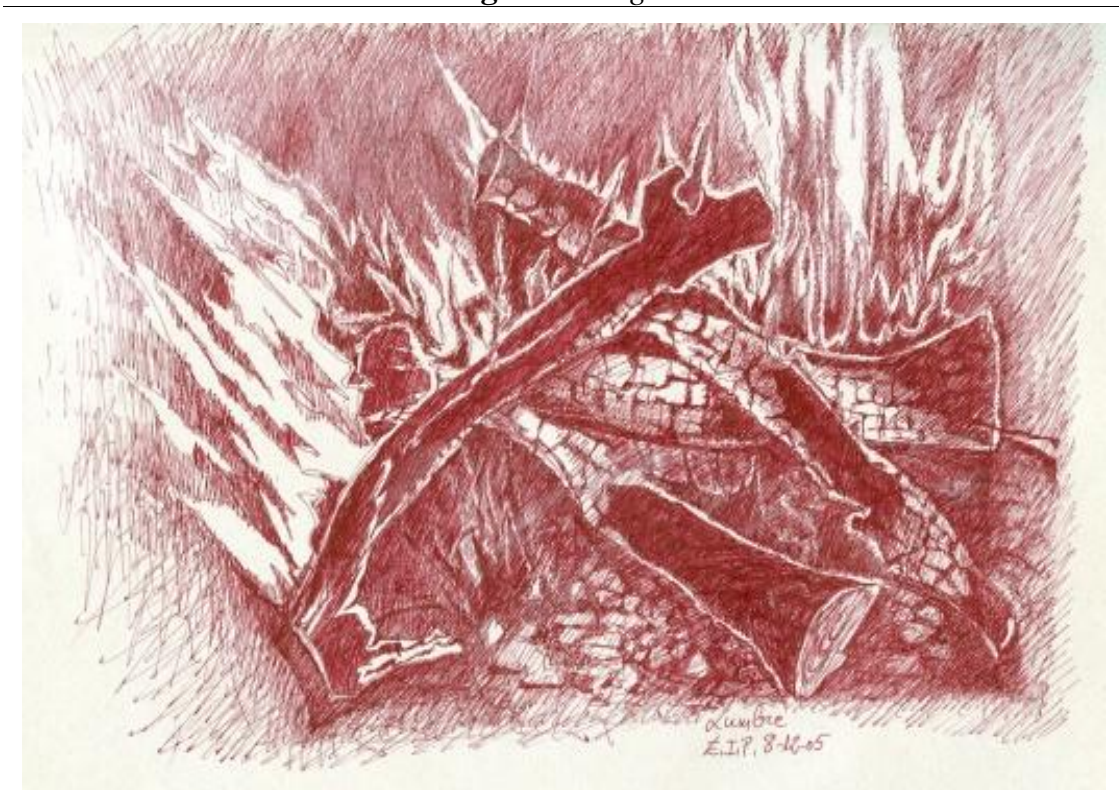

FUENTE: La autora, 2005. Tinta

Polígonos. Revista de Geografía, 21 (2011); pp. 259-281 
mente desaparecidas (ver FIG. 11), paisajes afectivos, imágenes mentales de este territorio, micro-paisajes que nos hablan de formas pretéritas para que la realidad se comprenda mejor invitándonos a la reflexión.

Fig. 5. $L u z$

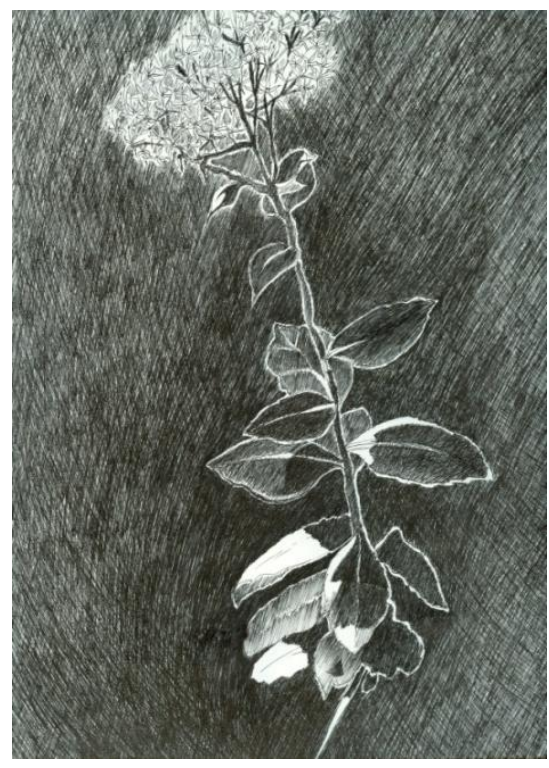

Fig. 7. Textura

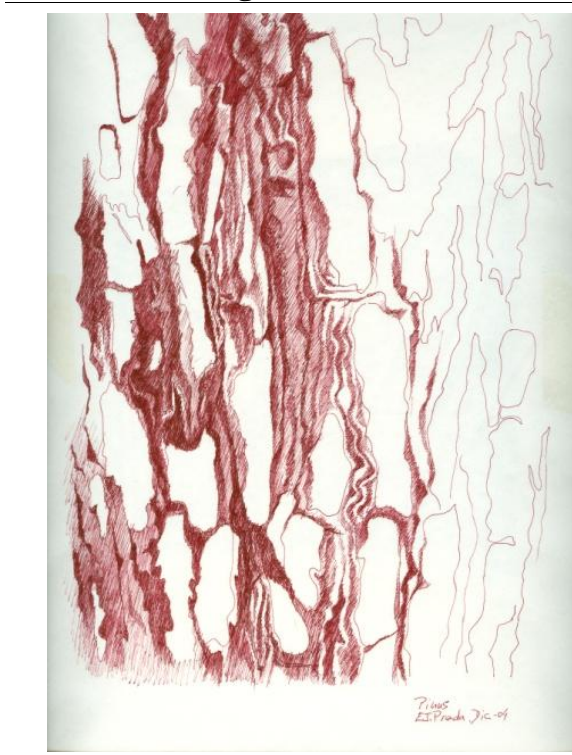

Fig. 6. Color

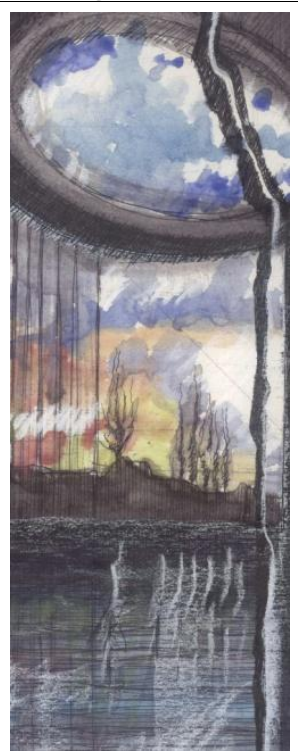

Fig. 8. Vertical

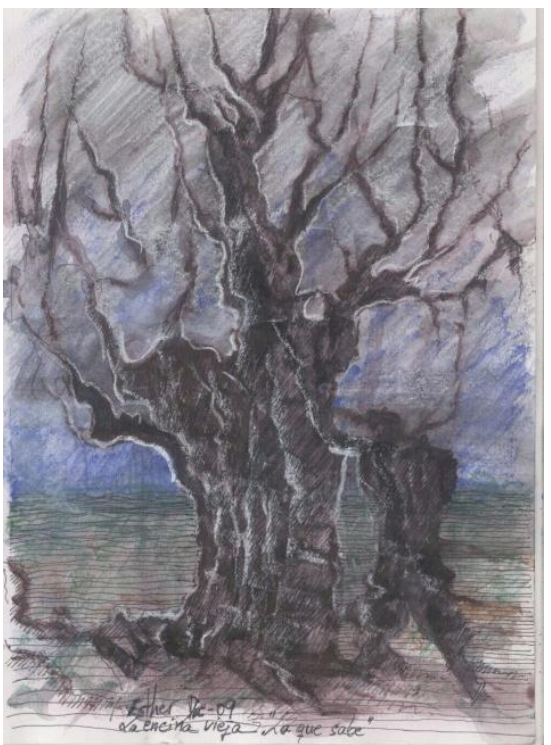

FuENTE: La autora, 2004, 2009. Tinta, lápiz y acuarela 


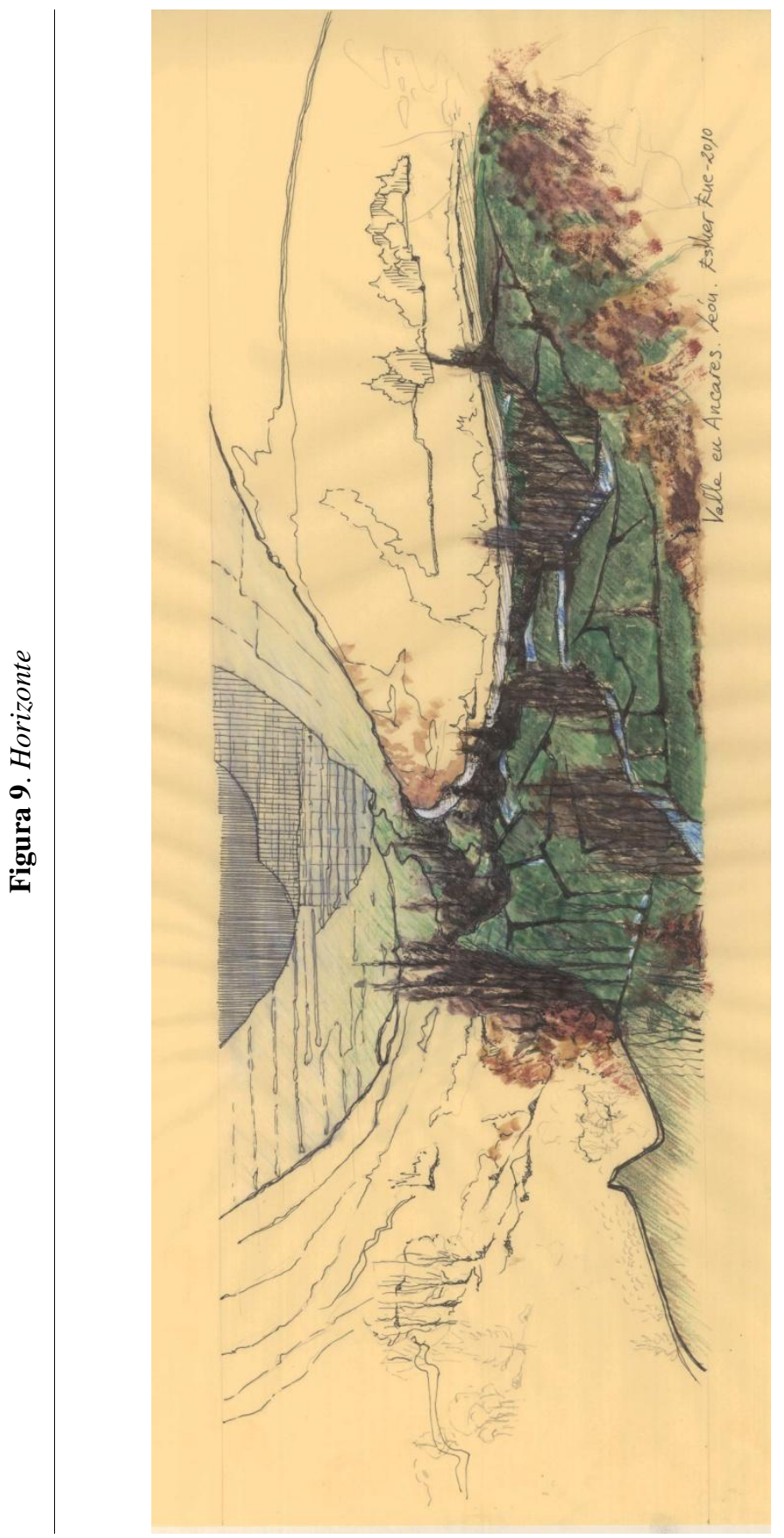

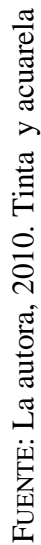

Polígonos. Revista de Geografía, 21 (2011); pp. 259-281 
Figura 10. Fragmento

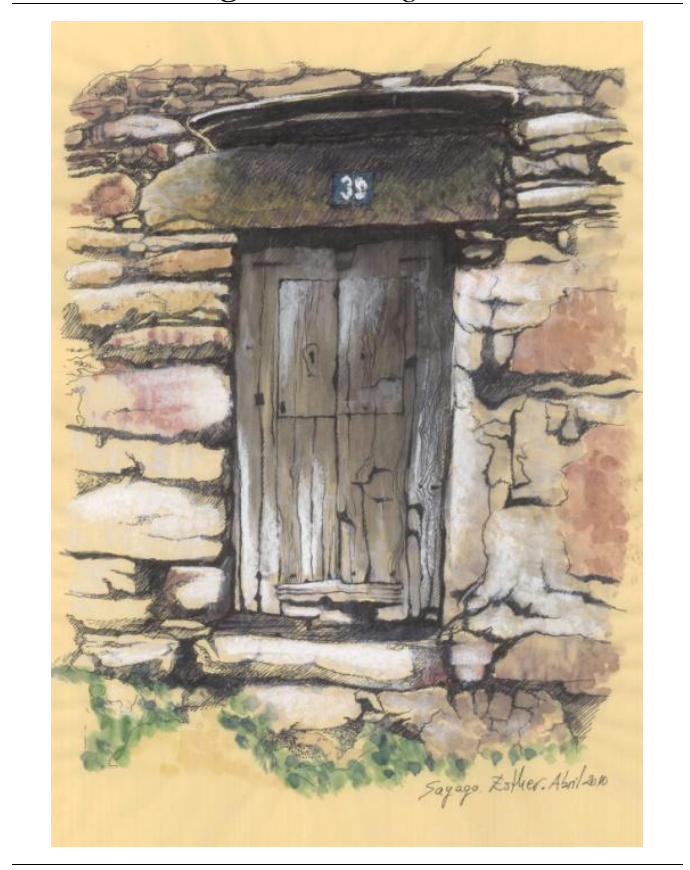

FUENTE: La autora, 2010. Tinta y acuarela

\section{ESCALAS DE CONTEMPLACIÓN}

Identificar este espacio patrimonial desde el ámbito geográfico al que pertenece, zona occidental de Castilla y León, fronteriza con Portugal, significa establecer su identidad como lugar a través de un inventario de los diferentes elementos que lo constituyen, fragmentos, micro-paisajes, restos de antiguos comunales en la escala del territorio, de morfologías urbanas laxas o compactas en función de su estructura tradicional ganadera o agrícola en los núcleos de población y de casas de labranza en la escala de la arquitectura, reflejando y evocando estos paisajes afectivos, el modelo del territorio social característico de este espacio.

Mediante la expresión gráfica se establece la lectura de este paisaje como un sistema, explicando y resumiendo cada elemento en su escala, identificando las partes que lo componen, de manera que pueda comprenderse la estructura reconociendo los principios de organización involucrados, a través de sus elementos constituyentes.

La complejidad de los paisajes da lugar a la manifestación u ocultación, a medida que se recorren las escalas de contemplación, de elementos o propiedades entendidas como rasgos del sistema que sólo son pertinentes en una 
determinada escala, a otras escalas, estos rasgos dejan de ser perceptibles o relevantes. Ello es común en sistemas complejos, tal es el paisaje agrario, cuya organización supone varias escalas como se ha expuesto, en lo espacial y en lo temporal, lo que engendra un comportamiento global que no se deduce directamente de las partes componentes (RIESCO, 2008).

Se clasifica mediante un sistema taxonómico gráfico el paisaje agrario de tres comarcas, Valduerna, Sayago y Vitigudino pertenecientes a las provincias de León, Zamora y Salamanca respectivamente. Estos paisajes son heterogéneos en su composición (ver FIG. 11) y dependientes de la escala, dado que se originan por interacción entre factores físicos, biológicos y antrópicos, cuyos radios de influencia y dinámicas propias son variados, lo cual da lugar a los diferentes mosaicos que componen la totalidad del sistema.

Tal sistema supone el instrumento básico que permite establecer la singularidad de un lugar, relacionando en una tabla de etapas o escalas (ver FIG. 12),- tabla que ya comentamos identificando y caracterizando la suma de informaciones naturales y antrópicas para la comarca de Sayago (PRADA, 2001)-, los contenidos de distinto contexto espacio-temporal según una secuencia vertical, así como establecer una lectura en la banda horizontal en un recorrido de lectura de izquierda a derecha, sobre las relaciones que se establecen entre los elementos de un mismo territorio percibido desde la intimidad y evocado a través del dibujo, influyendo en la expresión visual, los componentes reconocibles de las diferentes etapas de aproximación (ver FIG. $13)$.

Esta estructura muestra el funcionamiento de un mosaico de sistemas que interrelacionaban entre sí sobre este espacio, el ámbito geográfico del occidente de Castilla y León.

El debate en torno al modelo de territorio generado por concentraciones parcelarias genéricas, modelos constructivos que podríamos llamar estilo universal por contraposición a la arquitectura vernácula, que dejan como algo testimonial o caduco su antigua especificidad económica, cultural o arquitectónica, a la vez que se suplanta el patrimonio inmobiliario preexistente España es líder europeo en destrucción de patrimonio inmobiliario(NAREDO, 2004), contribuyen a desorganizar los sistemas agrarios, extendiendo la huella de deterioro ecológico hacia lugares cada vez más alejados.

Con ritmo acelerado nuestros paisajes tradicionales van perdiendo singularidad, como si quisieran reducir su historia y hacerse homogéneos; parafraseando a Julio Caro Baroja, van sujetando el país y la historia a la técnica (GÓMEZ DE MENDOZA, 2003). 


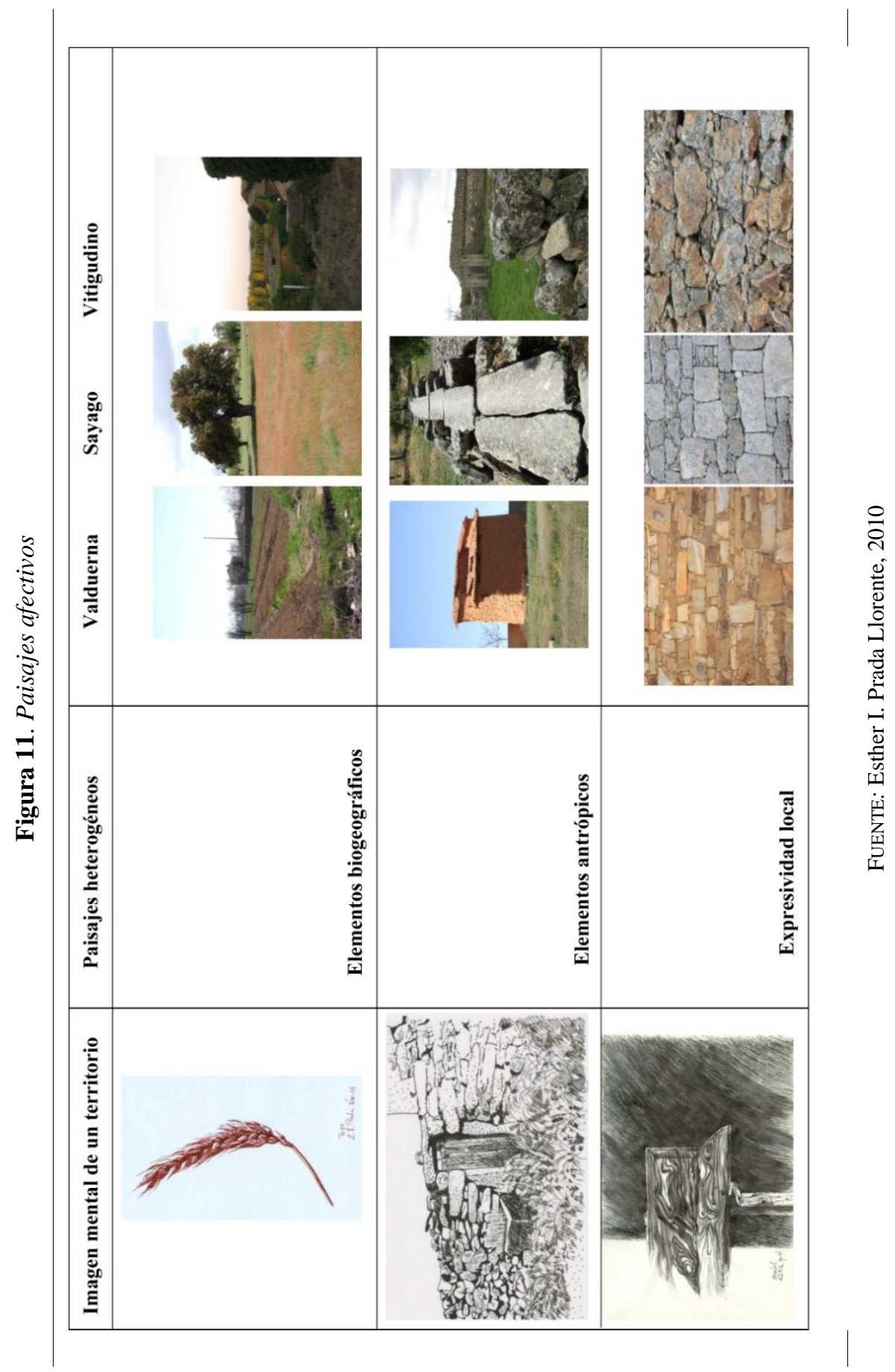

Polígonos. Revista de Geografía, 21 (2011); pp. 259-281 


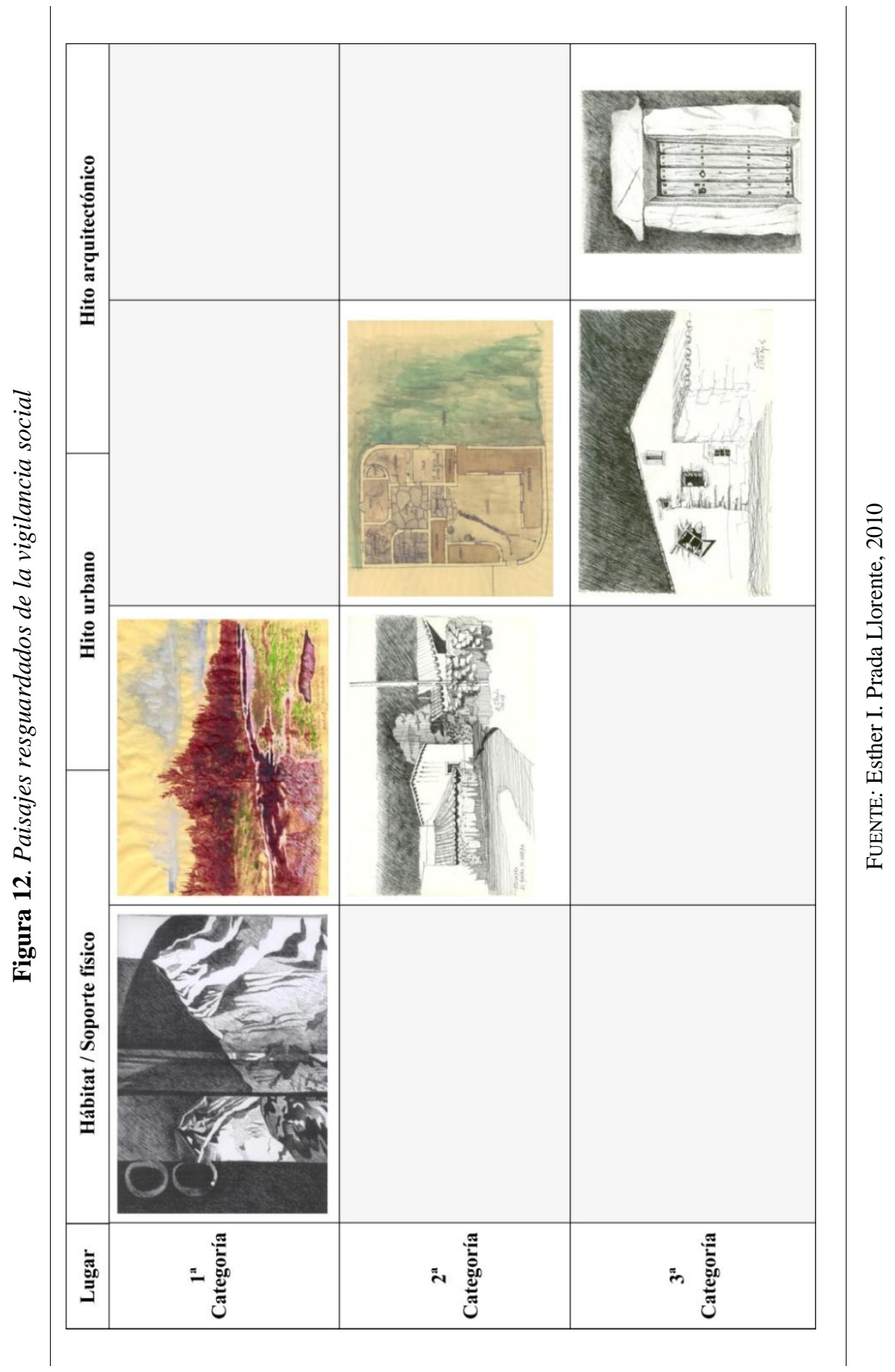

Polígonos. Revista de Geografía, 21 (2011); pp. 259-281 


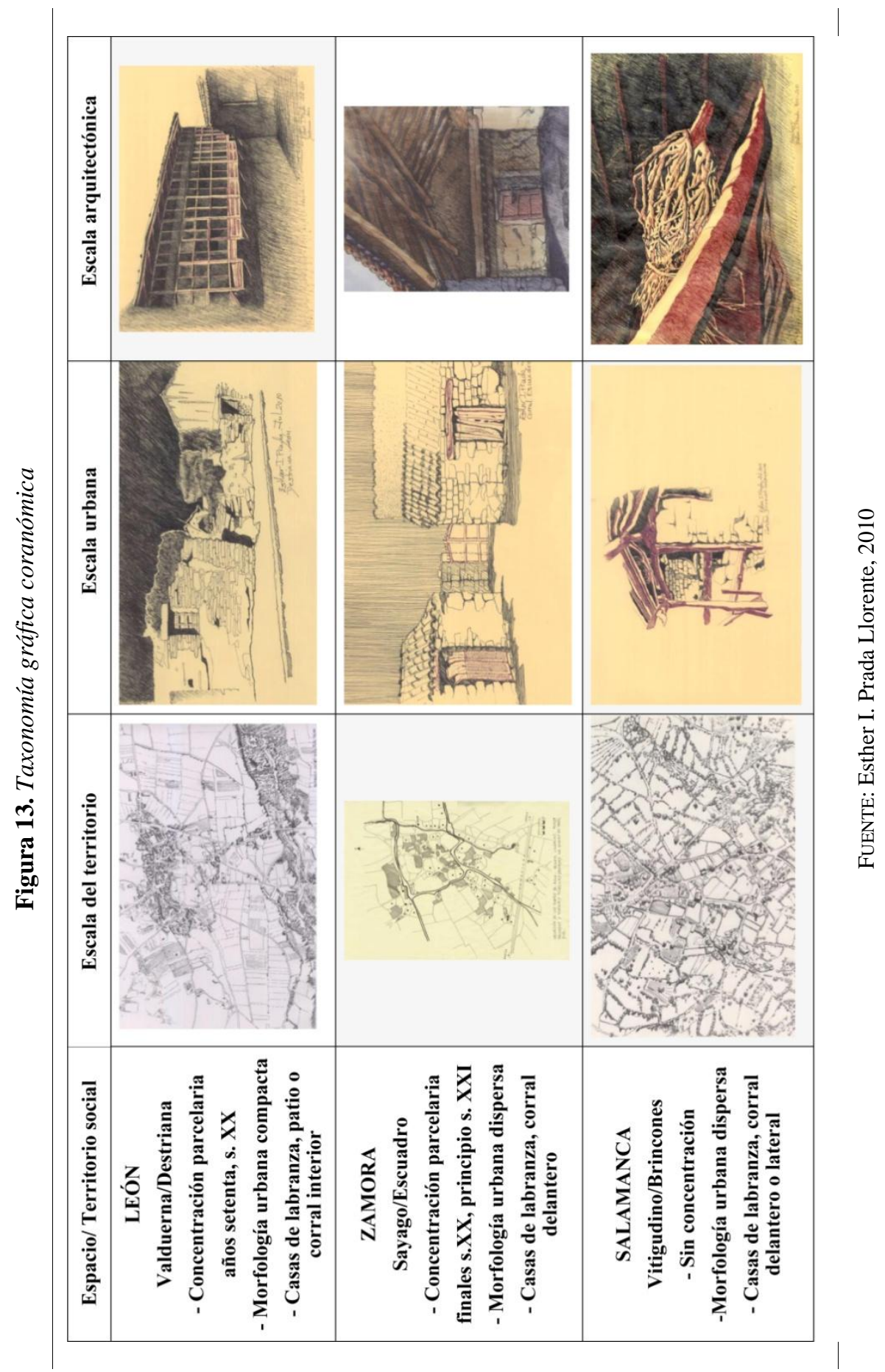

Polígonos. Revista de Geografía, 21 (2011); pp. 259-281 


\section{CONCLUSIONES}

El paisaje nos habita, cada uno poseemos el nuestro, fruto de una mirada particular. En la construcción de nuestros paisajes interiores intervienen tanto el recuerdo, como los sentidos que tal vez acompañaron la contemplación primera, sensaciones que forman parte de nuestra personal consideración estética del paisaje. Toda una herencia cultural, inevitablemente rural, pesa a la hora de enfrentarnos a su visión. Son nuestros paisajes del alma, los que sentimos como nuestros desde la infancia, y que ahora, atrapados en la temporalidad de estos dibujos, nos piden ser contemplados, meditados, estableciendo un camino que reconduzca la mirada.

Un camino es una posibilidad, una ruta siempre abierta dónde el deseo es quién perfila el recorrido, lleno de sueños, de huellas, encuentros, despedidas..., su trazado, precisa lentitud excluyendo el exhibicionismo. Falta el mundo que aliente esta empresa, la experiencia y el conocimiento de una comunidad, una manera concreta de hacer, un sistema, habiendo corrido veloz el tiempo que nos ha traído hasta aquí .

La ecología nos enseña que las perspectivas de evolución de un sistema, dependen de su flexibilidad para reaccionar ante los nuevos acontecimientos, en función de las señales que sobre ellos le envían sus circuitos de información, pero la información ni se capta de modo homogéneo ni fluye por igual a todos los niveles (NAREDO, 2004).

Los procesos indicados en el occidente castellano-leonés, están produciendo el cambio en el modelo territorial, en los sistemas de este ámbito geográfico, se está pasando de un mar de ruralidad o naturaleza poco intervenida en el que predomina la suavidad y blandura de los elementos del paisaje arcaico, que reflejan la flexibilidad, la transición continua, expresando lo local, como se muestra en el sistema escalar de contemplación-, hacia enclaves de campo o naturaleza, cuyo deterioro se inscribe en la serie de cambios culturales, sociales y económicos que generan monotonía inexpresiva.

Aún en la ausencia de tratamientos explícitos de su paisaje, la deslocalización en proceso nos debería hacer obtener una gama de prioridades para entender el territorio tal y como va siendo modificado por la acción humana.

"Deslocalización. No sólo quiere decir trasladar la producción y los servicios a zonas en donde la mano de obra es más barata, sino que también se refiere al plan de destruir el estatus de todos los lugares que antes se consideraban permanentes, de tal modo que el mundo entero se convierta en un No Lugar y en un único mercado líquido".

De A para X, Berger 2009 
Construir la propia casa, aquella casa popular y el lugar que evocamos, es hoy tal vez una quimera irrealizable que explicaría nuestra obsesión por retener ese tiempo definitivamente perdido en las imágenes aquí mostradas. Al menos, a la vista de estos dibujos alguien recordará que esa vieja puerta, muro o pared, antaño fue hogar y un día tejió la urdimbre de los pueblos. Tal vez por ello nos atrae su armonía, la medida humana de esta arquitectura en la que nos reconocemos.

Me pregunto si nuestras técnicas pueden aspirar aún a construir territorios en los que la experiencia del Lugar vuelva a ser posible, enderezando el rumbo general que nos hace vislumbrar John Berger.

\section{Figura 14}

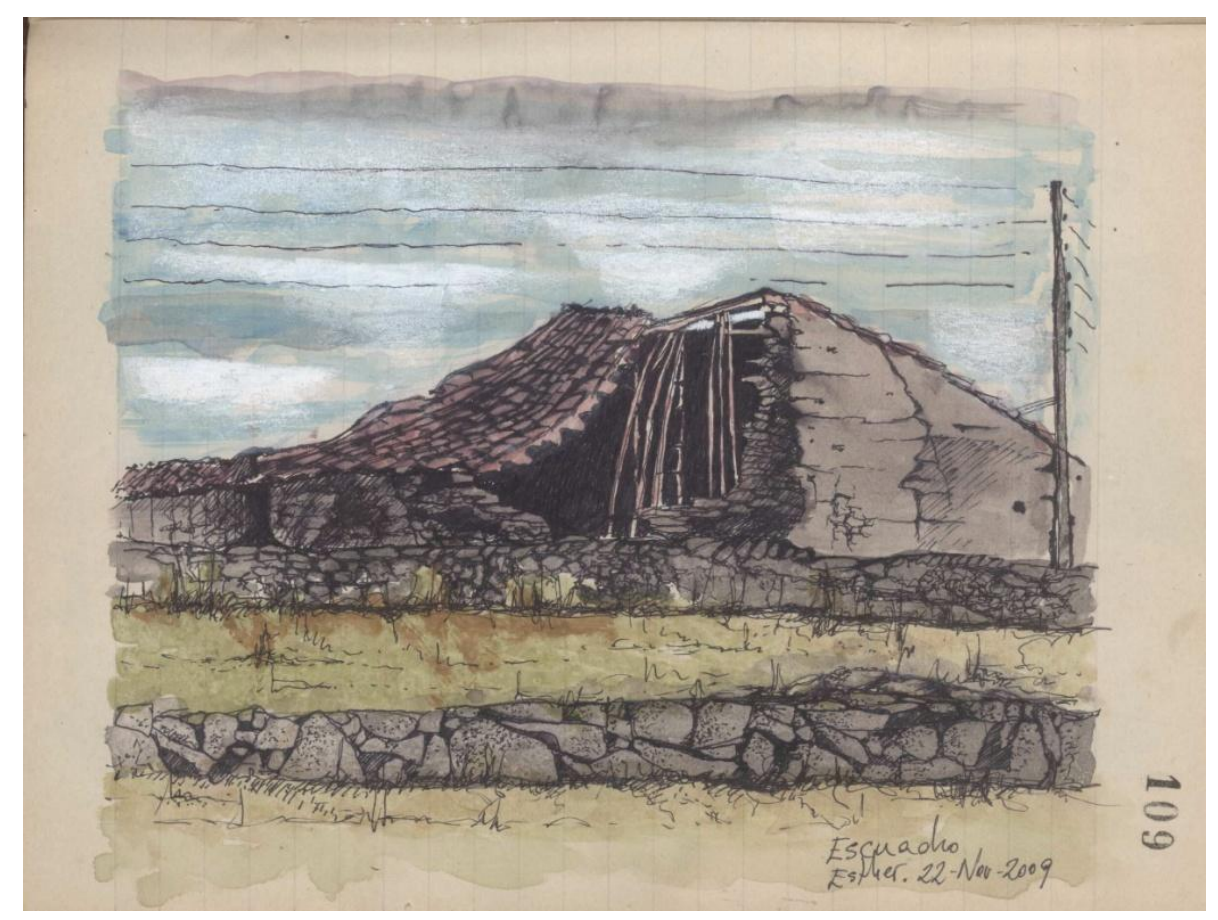

FUENTE: La autora, 2009. Tinta y acuarela

\section{BIBLIOGRAFÍA}

BÁEz MEZquita, J. M (2008): Espacios. Universidad de Valladolid.

BERGER, J. (2009): De A para X. Una historia en cartas. Alfaguara. Madrid.

BERGER, J. (2000): Algunos pasos hacia una pequeña teoría de lo visible. Árdora

Ediciones. Madrid 
Cabo Alonso, A. (1956): «El colectivismo agrario en Tierra de Sayago». En Estudios Geográficos $n^{\circ}$ 56, 593-658. Instituto Juan Sebastián Elcano. CSIC. Madrid.

GARCíA-Bellido GARCía DE DIEGO, J. (1999): Coranomía. Tesis doctoral. Escuela Técnica Superior de Arquitectura. Universidad Politécnica de Madrid.

Gómez DE MEndozA, J. (2003): «Naturaleza y Ciudad. Diseño urbano con criterios ecológicos, geográficos y sociales». En Boletín $C F+S$ 32-- IAU+S: La Sostenibilidad en el Proyecto Arquitectónico y Urbanístico. http://habitat.aq.upm.es/ boletin/n32/ajgom.html

MARTíNEZ DE PISÓN, E. (2006): «Los componentes geográficos del paisaje». En Paisaje y pensamiento. Dir. Javier MADERUELO. Madrid. Abada Editores.

NAREDO, J.M. (2004): «Diagnóstico sobre la sostenibilidad: la especie humana como patología terrestre». En Boletín $C F+S$ 32-- IAU+S: La Sostenibilidad en el Proyecto Arquitectónico y Urbanístico. http://habitat.aq.upm.es/boletin/n32/ajnar. $\underline{\mathrm{html}}$

PRADA Llorente, E. (2010): «Concentración espacial de la propiedad de la tierra, megaproyectos inmobiliarios y transformación del paisaje: caso Valdeluz». En Ciudad y Territorio. Estudios territoriales, $n^{o}$ 163, 49-66. Ministerio de la Vivienda. Madrid.

PRADA LlORENTE, E. (2005): «Paisaje agrario: antropología de un territorio». En Ciudad y Territorio. Estudios territoriales, $n^{o}$ 144, 343-372. Ministerio de la Vivienda. Madrid.

PRADA LlORENTE, E. (2007): «Paisaje agrario: antropología de un territorio II». En Ciudad y Territorio. Estudios territoriales, $n^{\circ} 154,689-709$. Ministerio de la Vivienda. Madrid.

PRADA LlORENTE, E. (2001): Sayago: Evolución histórica y proyección futura de su estructura territorial. Tesis Doctoral. Departamento de Ideación Gráfica. Escuela Técnica Superior de Arquitectura. Biblioteca virtual de la Universidad Politécnica de Madrid.

Prada Llorente, E., Riesco Chueca, P. (2010): «Buenas Prácticas Paisajísticas en la modernización agraria». Ponencia en XV Coloquio de Geografía Rural (Cáceres, Abril de 2010). Universidad de Extremadura.

Riesco Chueca, P., Gómez Zotano, J., Álvarez SAlas, D. (2008): «Región, Comarca, Lugar: Escalas de referencia en la metodología del paisaje». En Cuadernos Geográficos. $N^{o} 43,227-255$. Universidad de Granada. 